Review

\title{
Alaria alata in Terms of Risks to Consumers' Health
}

\author{
Weronika Korpysa-Dzirba ${ }^{1, *}$, Mirosław Różycki ${ }^{1}$, Ewa Bilska-Zając ${ }^{1}$, Jacek Karamon ${ }^{1}{ }^{\mathbb{D}}$, Jacek Sroka ${ }^{1}$, \\ Aneta Bełcik ${ }^{1}$, Magdalena Wasiak ${ }^{2}$ and Tomasz Cencek ${ }^{1}$ (D) \\ 1 Department of Parasitology and Invasive Diseases, National Veterinary Research Institute, \\ Partyzantow Avenue 57, 24-100 Pulawy, Poland; mrozycki@piwet.pulawy.pl (M.R.); \\ ewa.bilska@piwet.pulawy.pl (E.B.-Z.); j.karamon@piwet.pulawy.pl (J.K.); jacek.sroka@piwet.pulawy.pl (J.S.); \\ aneta.belcik@piwet.pulawy.pl (A.B.); tcencek@piwet.pulawy.pl (T.C.) \\ 2 Department of Pathology, National Veterinary Research Institute, Partyzantow Avenue 57, \\ 24-100 Pulawy, Poland; magdalena.wasiak@piwet.pulawy.pl \\ * Correspondence: weronika.korpysa@piwet.pulawy.pl
}

Citation: Korpysa-Dzirba, W.;

Różycki, M.; Bilska-Zając, E.;

Karamon, J.; Sroka, J.; Bełcik, A.;

Wasiak, M.; Cencek, T. Alaria alata in Terms of Risks to Consumers' Health. Foods 2021, 10, 1614. https://doi.org/ 10.3390 /foods 10071614

Academic Editor: Mary

Anne Amalaradjou

Received: 2 June 2021

Accepted: 9 July 2021

Published: 13 July 2021

Publisher's Note: MDPI stays neutral with regard to jurisdictional claims in published maps and institutional affiliations.

Copyright: (c) 2021 by the authors. Licensee MDPI, Basel, Switzerland. This article is an open access article distributed under the terms and conditions of the Creative Commons Attribution (CC BY) license (https:// creativecommons.org/licenses/by/ $4.0 /)$.

\begin{abstract}
Alaria alata flukes are cosmopolitan parasites. In Europe, the definitive hosts are red foxes (Vulpes vulpes), wolves (Canis lupus), and raccoon dogs (Nyctereutes procyonoides), as well as animals that belong to the Felidae family. Intermediate hosts, such as snails and frogs, are the sources of infection for definitive hosts. The developmental stages of A. alata mesocercariae may occur in paratenic hosts, including many species of mammals, birds, and reptiles, as well as in wild boars (Sus scrofa), which are important from the zoonotic point of view. Because there are no regulations concerning the detection of $A$. alata in meat, this fluke is usually detected during official obligatory Trichinella spp. inspections. However, a method dedicated to A. alata detection was developed. The growing popularity of game and organic meat has led to an increased risk of food-associated parasitic infections, including alariosis, which is caused by the mesocercarial stage of A. alata. The aim of this article is to highlight the problem of $A$. alata as an emerging parasite, especially in the terms of the increasing market for game and organic meats that have been processed with traditional methods, often without proper heat treatment.
\end{abstract}

Keywords: Alaria alata; parasite; risk; meat; venison; pork; one health

\section{Introduction}

Alaria alata is a widespread trematode that is considered a potential cause of a human disease called alariosis, which is associated with the consumption of raw or undercooked meat of intermediate (snails, frogs) or paratenic (mainly game) hosts of this parasite.

In recent years, a growing population of wild boars (Sus scrofa) has been reported in Europe. However, since 2018, a decrease in the number of these animals has been observed because of African swine fever or preventive actions undertaken in the European Union against the spread of this disease [1]. Another reason for this decrease is the greater popularity of hunting in Europe and the greater interest in venison products. The meat of wild boars is low in fat, has a high content of wholesome protein, and has a higher level of iron in comparison with pork, poultry, and beef. In addition, it has a very low level of cholesterol and a high content of unsaturated fatty acids, vitamins (thiamine and riboflavin), and minerals (sodium and potassium) [2]. Thus, it is considered an element of a healthy diet. This has resulted in an increase in the consumption of game meat as well as risks related to food-associated parasitic infections, including those caused by Alaria alata $[3,4]$. The $A$. alata species is mainly found in Europe, whereas on other continents, there are other species of this trematode, such as A. americana, A. mustelae, A. intermedia, and A. marcianae [5-7]. Epidemiological studies have shown that this parasite is widespread in various environments because of its broad range of possible paratenic hosts, including many species of birds, amphibians, reptiles, and mammals [8-11]. However, a key role in the life cycle of $A$. alata is played by snails, frogs, and tadpoles, which is 
why the aquatic environment is the most conducive for the spread of this parasite [12] Wójcik et al. (2002) showed that the percentage of snails and frogs infected by A. alata larvae depends on the season, ranging from $30 \%$ in autumn to $100 \%$ in spring. This availability of snails and frogs infected with $A$. alata makes them an important source of infection for definitive and paratenic hosts. Because of their feeding habitats, wild boars are considered the main source of $A$. alata for humans $[13,14]$. Wild boars play a much greater role in the spread of $A$. alata than farm animals, such as pigs. However, the growing popularity of free-range animal farming raises the possibility of the infection of domestic pigs that are kept outdoors $[11,15]$. There is consumer demand for ecological products as well as those manufactured using traditional and natural methods; nevertheless, in recent decades, the amount of ecological production of meat in the European Union has remained at $3 \%$ of the total meat production. In 2017, about $5 \%$ of cattle, $6 \%$ of sheep and goat, and $3 \%$ of poultry production were classified as organic, whereas in the entire pig farming sector, ecological farming accounted for less than $1 \%$ of total production. Still, the ecological production of pigs and poultry shows an upward trend [15]. A questionnaire completed by participants in proficiency tests concerning Trichinella spp. organized by the National Veterinary Research Institute in Poland revealed that the mesocercarial stage of A. alata, which is known as Distomum musculorum suis (DMS) (a term that is currently rarely used), was occasionally found during examinations of the meat of pigs and wild boars for Trichinella spp. (unpublished data). This situation is probably similar in other countries, where the reference method for Trichinella spp. detection is used. Until recently, the presence of mesocercariae in meat was considered only a quality defect with no threat to human health. However, by consuming raw or undercooked venison, pork, frog legs, or snails containing larval forms of $A$. alata, humans become paratenic hosts and may suffer from the symptoms of alariosis [10]. Sporadic reports of alariosis cases have resulted in the classification of this disease as an emerging disease [4]. The reports of alariosis in humans came mainly from the United States and Canada and were related to the American Alaria species. Nevertheless, it is undeniable that $A$. alata also has a pathogenic potential and may cause alariosis after the consumption of raw or semi-raw traditional and homemade products made from meat infected by mesocercariae [4]. The symptoms of this disease are usually not specific, and therefore, its diagnosis is very difficult. There are no public safety regulations for diagnosing meat containing $A$. alata, except for a statement in Regulation (EU) 2017/625 of the European Parliament and the Council that indicates that game meat in which parasites are found should be considered as unfit for consumption. Because there is no official method for the detection of $A$. alata, this trematode is mainly detected during official Trichinella inspections that use the artificial digestion method [16,17]. The aim of this article is to draw attention to the problem of the presence of $A$. alata in food and the emergence of new risks that have not yet been considered, such as the presence of this parasite in the meat of wild boars and pigs from organic farms as well as in meat products that are processed without proper heat treatment.

\section{Characteristics of $A$. alata}

The adult stage of $A$. alata was described in 1782 by Goeze, whereas the larval stage of this parasite was revealed by Gestaldi in 1854 . Further descriptions of $A$. alata were made by Duncker, who studied the larval stages of these trematodes in swine muscles [18-22]. In 1842, Bugge identified a link between the presence of mesocercariae in frogs and pigs [23]. The relationship between $A$. alata and its mesocercarial larval stage, DMS, was demonstrated in 1953 [24]. Alaria alata belongs to the family Diplostomatidae and the genus Alaria. The species of this parasite inhabit different regions. Alaria alata is common in Europe, while $A$. mustelae, A. intermedia, A. marcianae, A. arisaemoides, $A$. canis, and $A$. taxideae can be found in North and South America [25-30]. The body of A. alata in the adult stage is 3 to $6 \mathrm{~mm}$ long and 1 to $2 \mathrm{~mm}$ wide, and it is divided into two sections. The front part of this fluke has a wing-like shape and ends in an additional clinging Brandes organ. It contains four clavate cells, which despite their glandular appearance do not have ducts [29]. 
However, according to recent research by Nacheva and Manikovskaya (2019), the Brandes organ is a morphofunctional unit that performs a primary function in the digestion of food by means of developed glandular structures, and it specializes in secretory activity [31]. The rear part of $A$. alata has a cylindrical shape and contains most of the internal organs (Figure 1).

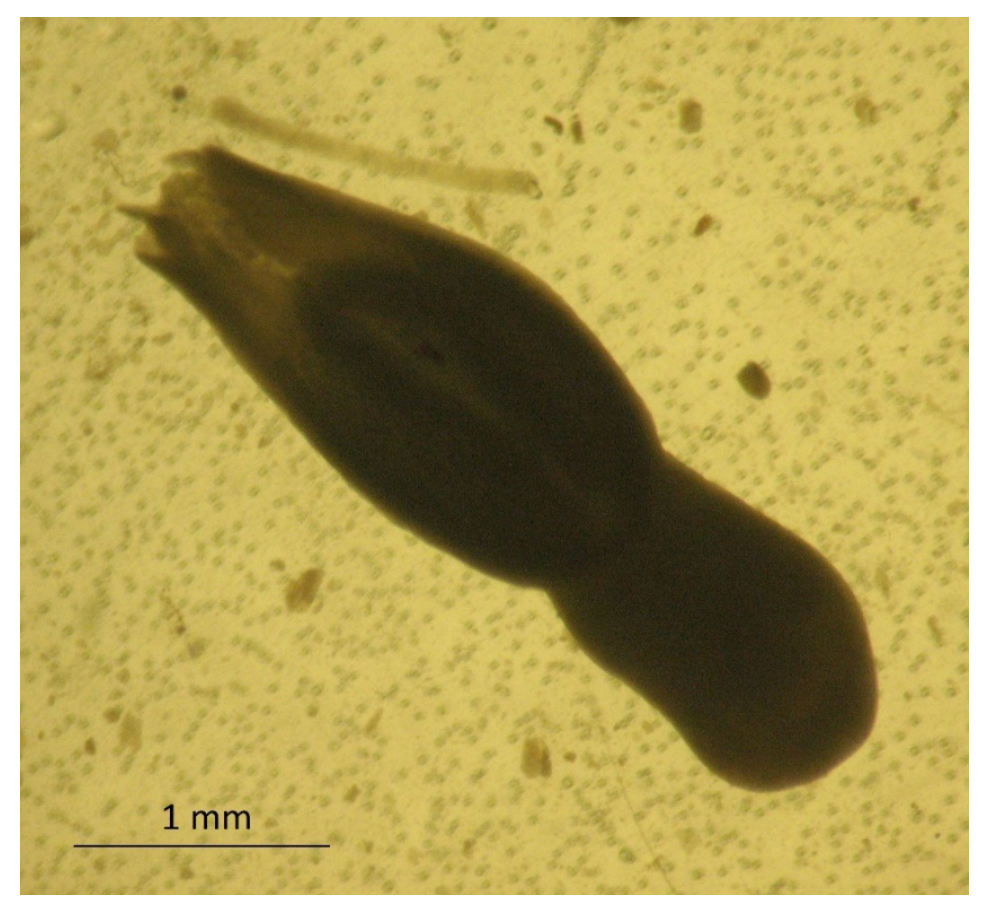

Figure 1. The adult stage of $A$. alata isolated from the small intestine of a red fox; $40 \times$ magnification (by J. Karamon).

The larval stage of $A$. alata has the shape of an oval, reaches up to $0.5 \mathrm{~mm}$ in length, and has fine parallel lines. It is equipped with a mouth and abdominal sucker [32] (Figure 2). In several studies, a series of electron microscopy photos of larval forms originating from wild boars revealed additional sucker-like surface structures.

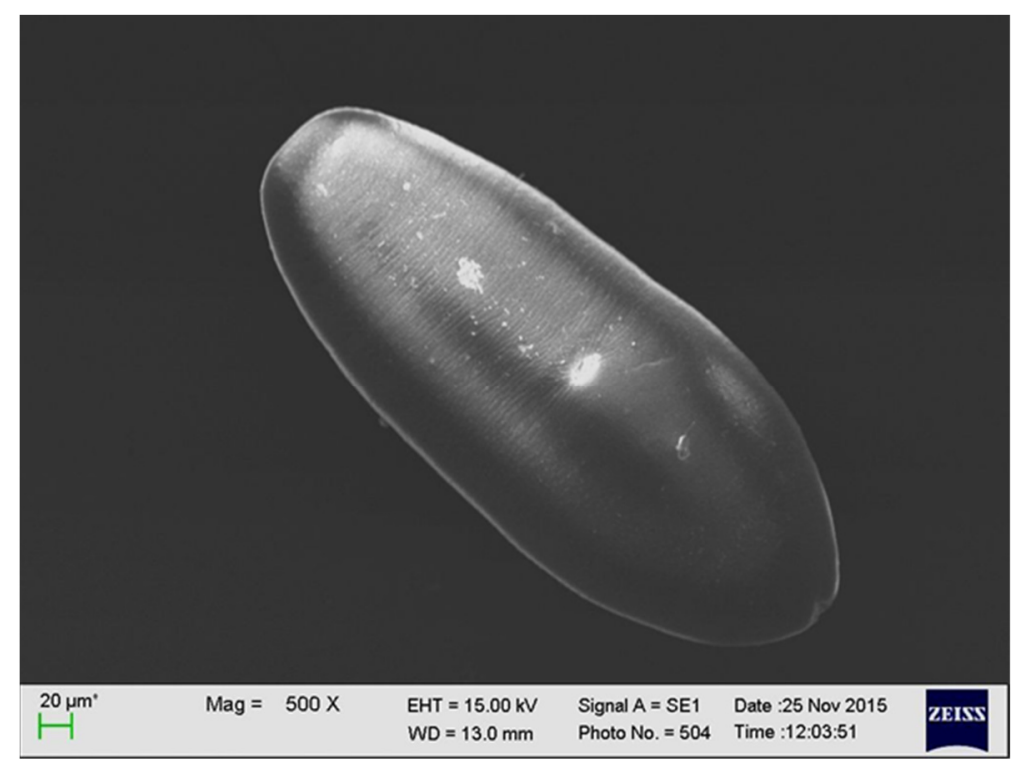

Figure 2. The larval stage of $A$. alata detected in the muscle tissue of a wild boar (by M. Wasiak). 


\section{Life Cycle of A. alata}

The life cycle of the Alaria genus is complex and involves definitive, intermediate, and paratenic hosts (Figure 3). The definitive hosts are carnivores, including foxes, wolves, raccoons, lynxes, martens, badgers, dogs, and cats [11,33,34]. They become infected by eating frogs or tadpoles that contain mesocercariae, whose length can reach up to $0.5 \mathrm{~mm}$ (Figure 4). These parasites migrate through abdominal and thoracic cavities or via the circulation to the lungs, where the mesocercariae enter the metacercarial stage. Next, they are swallowed and develop in the small intestine, reaching 3-6 $\mathrm{mm}$ in length and 1-2 $\mathrm{mm}$ in breadth as adult flukes [32]. In studies on the distribution of the parasites in the small intestines of foxes, A. alata were detected mostly in the anterior parts of the intestines in almost all infected foxes (99.4\%) [35]. Eggs (oval, size 98-125 × 62-81, light brown and operculated with a lid-operculum), which are a dispersive form of the parasite, are laid in definitive hosts and excreted with the feces into the environment. Miracidia, an invasive form of the parasite in intermediate hosts, are released from the eggs in aquatic environments, and they infect the first intermediate hosts, which are freshwater snails (e.g., Helisoma, Planorbis spp.). The miracidia develop into sporocysts that hatch a fast-moving larval stage-cercariae-which leave the snails, penetrate tadpoles or frogs, and develop into non-reproductive mesocercariae. The consumption of these amphibians by carnivores completes the life cycle of $A$. alata. However, as mentioned before, the life cycle of this parasite can also involve paratenic hosts, such as wild boars, mice, rats, martens, polecats, and pigs, as well as wild birds and some species of snakes and lizards. Similarly to the definitive hosts, they can be infected by eating mesocercariae from intermediate (tadpoles or frogs) or other paratenic hosts [12,33,34]. Within these hosts, the mesocercariae do not reach the stage of adult flukes; however, they can survive for months in the connective tissues between muscles or the adipose tissue, which constitute a kind of reservoir of this fluke for definitive hosts or other paratenic hosts. The migration of the mesocercariae from one paratenic host to another does not reduce the infectivity of the parasite [32]. In addition, humans can become paratenic hosts by consuming mesocercariae that are present in raw or undercooked game, pork, frog legs, or snails [10]. Infections with A. alata in humans cause alariosis.

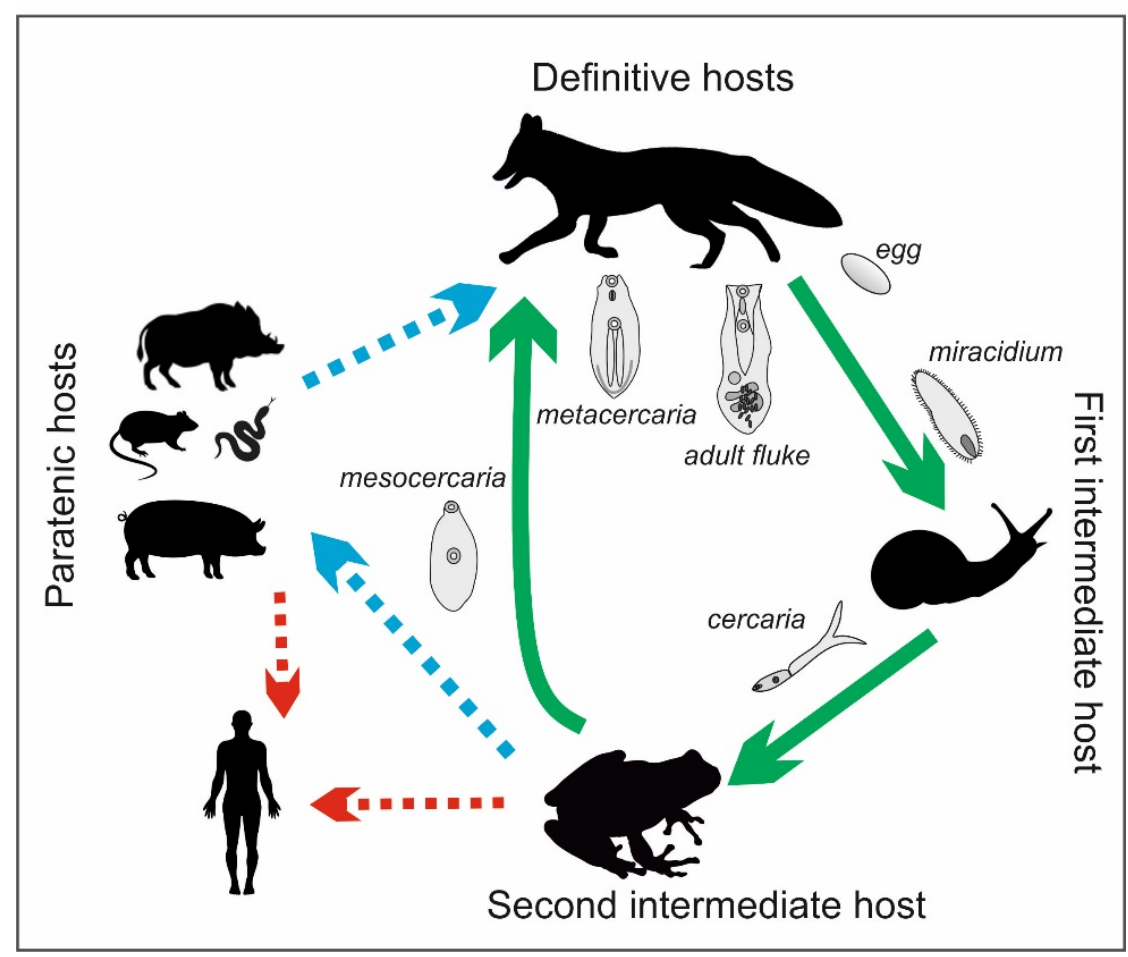

Figure 3. Life cycle of A. alata (by J. Karamon). 


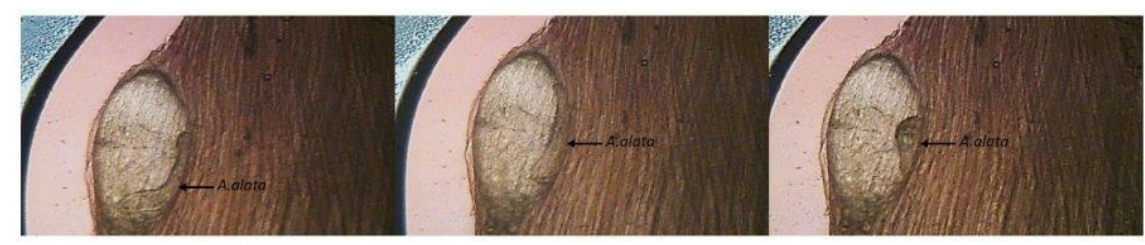

Figure 4. A. alata movement sequence in a muscular cyst of a wild boar (by M. Różycki) (the movie showing movement of A.alata is included in the Supplementary Materials Video S1).

\section{Detection of A. alata in Definitive and Paratenic Hosts}

The presence of adult flukes in definitive hosts is mainly connected with the microscopic detection of eggs in fecal samples or post-mortem parasite recovery from intestinal content. However, the diagnosis of $A$. alata infection in the meat of paratenic hosts is performed during inspections for Trichinella spp. Therefore, most reports of the presence of A. alata in wild boar meat in the literature come from tests for the presence of Trichinella spp. using the reference magnetic stirrer method with artificial digestion (MSM) according to ISO 18743 [17]. This technique is not dedicated to the detection of flukes of Alaria spp. In 2006, the German Federal Institute for Risk Assessment pointed out the existence of a risk of infection with alariosis for game consumers [36]. At that time, because of the lack of an appropriate method for detecting this parasite, the real number of infected wild boars could not be determined. Therefore, in 2010, the mesocercaria migration technique (AMT) was developed for the detection of $A$. alata. In the AMT, a sample of minced meat weighing $30 \pm 2 \mathrm{~g}$ is transferred to a strainer, which is placed in a funnel and immersed in warm water $\left(46-48^{\circ} \mathrm{C}\right)$. After $90 \mathrm{~min}, 20 \mathrm{~mL}$ of the liquid is drained into a measuring cylinder and then into a Petri dish or larval counting basin, and it is viewed under a stereomicroscope or trichinoscope at a magnification of 15-20× [32]. Subsequently, German researchers used the method described above to examine archived wild boar meat samples that were classified as not containing A. alata mesocercariae during the detection of Trichinella spp. with the artificial digestion method. The AMT showed that $11.5 \%$ of the samples tested contained A. alata mesocercariae [10]. The limited possibility of detecting A. alata mesocercariae using artificial digestion was caused by their lower resistance to the digestive fluid (HCL/pepsin), which damaged the parasites and caused the loss of their characteristic mobility, making their identification difficult. Due to their characteristic shape and size, A. alata mesocercariae often do not reach the final stage of the MSM (examination of sediments) because they stay in the strainer. Therefore, one of the reasons for the low detection of mesocercariae with the MSM may also be the inadequate diameter of the mesh size in the sieves used for the tests [37]. However, according to ISO 18743:2015, which has been indicated as a reference method in the EU Commission Regulation 2020/1478 since October 2020, the diameter of the mesh size may vary from 180 to $200 \mu \mathrm{m}$. A larger mesh size may provide a greater possibility for the detection of $A$. alaria mesocercariae. Moreover, these parasites are most often located in the layer of connective tissue between the muscles, especially where there is a large amount of adipose tissue; however, for MSM testing for trichinosis, it is advised that samples are free of fat and fascia [38]. As a result, in official statistics, the presence of A. alata might be underreported. Studies were also conducted in Latvia to determine the level of potentially false-negative results found using the MSM compared with the level in the results obtained using the AMT. In these analyses, it was found that $40 \%$ of the samples tested with the MSM contained A. alata mesocercariae, but after using the AMT, this percentage increased to $76.7 \%$. In addition, a significant difference in the number of mesocercariae detected was observed. Their number per gram ranged from 0.02 to 1.22 when using the AMT and from 0.02 to 0.56 when using the MSM. In 13 $(21.7 \%)$ samples, mesocercariae were found only on the sieve during the ASM test. This number indicates that these samples were false negatives when tested with the MSM [37]. In studies performed in the Czech Republic between 2012 and 2013 with the AMT, the percentage of wild boar meat samples containing A. alata mesocercariae was $6.8 \%$; however, when using the MSM, no mesocercariae were found in any of the 221 samples tested [39]. 
In Lithuania, during routine tests for the detection of Trichinella spp., the percentage of simultaneously detected samples containing A. alata mesocercariae was 7\% [37]. In Poland, veterinary inspectors observed the presence of $A$. alata during regulatory testing of wild boar carcasses for trichinellosis. A questionnaire was sent to participants in proficiency tests for Trichinella spp. detection in Poland in 2020 (489 participants), which revealed the occurrence of mesocercariae in wild boar meat samples at the level of $4 \%$. According to the data obtained, A. alata were found only in wild boars. However, according to data collected by the Veterinary Research Institute in Poland, 33\% of the wild boars inhabiting the southeastern region of Poland (which is rich in water reservoirs) were infected with mesocercariae (unpublished data).

\section{A. alata in Red Foxes in Europe}

Recently, an increase in the population of red foxes has been observed in Europe [40-44]. These animals increasingly approach human neighborhoods (in rural and urban areas) in search of food. Such close contact with foxes may result in the dispersion of invasive eggs into environments that pets and farm animals inhabit; therefore, it may represent a threat to human health [45]. Studies conducted in Spain confirmed that the infection of foxes with $A$. alata is more common among wild animals that live near moist areas; this fluke was present in foxes that lived near rivers and was absent in foxes that inhabited the desert regions of southern Spain [46]. In addition, in Poland, the percentage of red foxes infected with $A$. alata varies significantly among different regions, as it depends on the presence of surface water. It was found that these differences ranged from $15.2 \%$ in the southern areas of Poland to $90 \%$ in the North [47]. A similar percentage (96\%) of foxes infected with A. alata was observed in Lithuania, a country bordering Poland to the northeast [48]. Tylkowska et al. (2018) observed that $54.7 \%$ of foxes from northwestern Poland were infected with A. alata, especially those living near water reservoirs [45]. By comparing these results with those of previous studies in the southern region of Poland, where the percentages of foxes with $A$. alata were $39.2 \%$ and $31.6 \%$, it can be concluded that there has been an increase in infections in this region [49]. An increase in the population of infected foxes was observed in Denmark - from 10.9\% in 1984 to $16.9 \%$ in 2014 [50,51]. Reports from Italy and Croatia showed that the numbers of red foxes with A. alata were low- $5.3 \%$ and $4.7 \%$, respectively [52,53]. In some European countries, including Great Britain and Greece, these trematodes were not found [54,55]. Generally, in Europe, the percentage of foxes infected by $A$. alata varies, with a very high or moderate to low prevalence of this trematode. The prevalence of $A$. alata in red foxes in Europe is summarized in Table 1.

Table 1. Prevalence of $A$. alata in red foxes in Europe.

\begin{tabular}{|c|c|c|c|}
\hline Country & $\begin{array}{l}\text { Foxes Infected } \\
\text { by A. alata }(\%)\end{array}$ & $\begin{array}{l}\text { Analysis } \\
\text { Method }\end{array}$ & References \\
\hline Poland & $15.2-0$ & $\mathrm{SCT}^{1}$ & [47] \\
\hline Lithuania & 96 & $\mathrm{SCT}^{1}$ & [48] \\
\hline Denmark & 16.9 & IST $^{2}$ & [51] \\
\hline Italy & 5.3 & $\mathrm{SCT}^{1}$ & [52] \\
\hline Croatia & 4.7 & $\begin{array}{c}\text { Microscopic examination } \\
\text { of intestinal } \\
\text { content }\end{array}$ & [53] \\
\hline Greece & 0 & $\begin{array}{l}\text { Sieving and } \\
\text { sedimentation }\end{array}$ & [54] \\
\hline Great Britain & 0 & $\begin{array}{l}\text { Scraping and } \\
\text { sedimentation }\end{array}$ & [55] \\
\hline
\end{tabular}

\footnotetext{
${ }^{1}$ Sedimentation and counting technique; ${ }^{2}$ intestinal scraping technique.
} 


\section{A. alata in Wild Boars in Europe}

In recent years, in some European countries, there has been an upward trend in the occurrence of $A$. alata mesocercariae in game animals $[3,10,39,56]$. The infection of wild boars with this fluke depends on the boars' exposure to sources of these parasites, and it is correlated with the number of foxes that are definitive hosts living in the same territory. By consuming parasitized snails, amphibians, or other paratenic or intermediate hosts that carry mesocercariae, wild boars become secondary paratenic hosts [32]. The larvae migrate from the intestinal lumen through the intestinal wall into the muscle, fat, and glandular tissues [57]. The appearance of $A$. alata mesocercariae in cysts in wild boars' muscle tissues is presented in Figure 4.

In France, between 2007 and 2011, 27,582 samples of wild boar meat received from 502 hunting districts were tested using the MSM, and a relatively low rate $(0.6 \%)$ of $A$. alata mesocercariae infection was found. The positive samples came from $12 \%$ of the hunting districts, indicating that the presence of this parasite was not restricted to a specific area and that there was a risk of further spread [3]. From 2007 to 2014, the French National Reference Laboratory for Foodborne Parasites conducted a survey that showed that the strongest circulation of this fluke in wild boars occurred near the rivers in the northeastern and central regions of France [58]. According to French regulations, testing for Trichinella spp. in wild boars intended for personal consumption is voluntary; thus, the real prevalence might be underestimated. An evaluation of data on the prevalence of $A$. alata in wild boars in Germany showed that $0.02 \%$ to $3.06 \%$ of them were infected. However, these results were based on the artificial digestion method; therefore, to estimate the real percentage of infected animals, the results mentioned above should be recalculated with a magnitude that is two to three times greater, resulting in a prevalence of $12 \%$ to $15 \%$ [10]. Studies carried out in Austria revealed that $4.3 \%$ of wild boars were infected with A. alata mesocercariae; among them, $86.4 \%$ of the positive samples were collected from the southern part of the country [57]. Results from 2013 to 2014, in which 6\% of 348 wild boar meat samples that were tested using the AMT contained A. alata mesocercariae, confirmed the relatively low average presence of this parasite in Austria. Considering the previous results, it was found that this parasite is enzootic in the floodplains along the Danube river and in the area bordering the Czech Republic, where studies by Paulsen et al. (2013) revealed that $6.8 \%$ of the wild boars were infected with A. alata [39,59]. In Poland, Strokowska et al. (2020) examined 221 meat samples from wild boars that were hunted in five provinces localized in the northeastern part of the country in order to detect $A$. alata using the AMT. The presence of mesocercariae was confirmed in $98(44.3 \%)$ carcasses. Such a high percentage of positive samples was probably due to the fact that in the area where the wild boars were found, there are many lakes, rivers, and swamps, which constitute an ideal living environment for intermediate hosts of this fluke [13]. In the same year, Bilska-Zając et al. (2020) published the results of research on the presence of $A$. alata in wild boars in the remaining 12 provinces in Poland. As part of this work, 3589 samples were tested with the AMT, and $151(4.2 \%)$ were found to be positive. The highest incidence of infections-60\% and $50 \%$-was found in two regions in northern Poland, while in samples from other voivodeships, the percentages were much lower (0-15.1\%). The differences in the obtained results were most likely related to the different environmental conditions in the individual regions [4]. In other parts of Europe, current data on the occurrence of this parasite are limited [14]. The prevalence of A. alata in wild boars in Europe is summarized in Table 2. 
Table 2. Prevalence of A. alata in wild boars in Europe.

\begin{tabular}{cccc}
\hline Country & $\begin{array}{c}\text { Wild Boars Infected } \\
\text { by A. alata (\%) }\end{array}$ & Analysis Method & References \\
\hline France & 0.6 & MSM $^{1}$ & {$[3]$} \\
\hline Germany & $0.02-3.06$ & MSM $^{1}$ & {$[10]$} \\
\hline Austria & $4.3-6$ & AMT $^{2}$ & {$[57,58]$} \\
\hline Czech Republic & 6.8 & AMT $^{2}$ & {$[39]$} \\
\hline Poland (northeast) & 44.3 & AMT $^{2}$ & {$[13]$} \\
\hline Poland (except northeast) & 4.2 & AMT $^{2}$ & {$[4]$} \\
\hline
\end{tabular}

${ }^{1}$ Magnetic stirrer method; ${ }^{2}$ mesocercariae migration technique.

\section{The Pathogenicity of $A$. alata}

The pathogenicity of $A$. alata is correlated with the intensity of infections caused by high levels of intake of mesocercariae. Studies conducted on experimentally infected primates revealed that repetitive intake of mesocercariae causes an increase in the number of eosinophils in the blood or tissues (eosinophilia) and an increase in serum immunoglobulin $\mathrm{E}(\mathrm{IgE})$, which may lead to a general anaphylactic reaction with symptoms of tachycardia, a drop in blood pressure until vasomotor collapse, and unconsciousness [32]. The migration of mesocercariae causes a polyphasic change in the muscles and subcutaneous lesions in paratenic hosts, such as wild boars. Studies conducted on European minks showed that this is indicated by the infiltration of mononuclear cells and the appearance of granulomatous tissues at different maturation stages, leading to muscular and subcutaneous fibroplasia. The inflammation most likely results from direct tissue damage rather than an immune reaction targeted toward the parasitic antigens [60]. The flukes are generally considered to be nonpathogenic for definitive hosts; however, intensive infections can be responsible for enteritis [61]. To date, the sources of human alariosis cases were frog legs and goose meat [62-64]. The symptoms of this disease range from low-grade respiratory and cutaneous symptoms to diffuse unilateral subacute neuroretinitis (DUSN) and anaphylactic shock, with possibly lethal consequences $[32,62,63,65,66]$. The pathogenicity of $A$. alata has been poorly studied because the symptoms described above were observed in humans infected with other species of Alaria spp.

\section{A. alata as a Potential Threat in the Production of Food of Animal Origin and Preventive Actions}

Humans may act as paratenic hosts; in some countries, depending on local dietary habits, they can be infected by eating frogs (frog legs) or any predators of frogs, among which the wild boar is the main source of infection [67]. Frog-eating birds (herons, birds of prey, etc.) must also be taken into account as a source of human infection, even though these are not very popular dishes and are not normally consumed. There are also other sources of infection, but they are highly unlikely; these include Mustelidae (badgers, weasels, otters, etc.), Procyonidae (raccoons and coatis), which have been found to harbor the mesocercarial stage in their tissues, and even reptiles $[9,14,68]$. The human hazards related to the consumption of meat products that contain mesocercariae of $A$. alata depend on various factors, such as prior freezing of the meat, the amount of meat consumed, and the methods used in the processing of the meat [57]. Freezing is recommended for inactivating many parasites, including Trichinella or Toxoplasma [69]. Gonzales-Fuentes et al. (2015) pointed out that freezing game meat to an internal temperature of at most $-13.7^{\circ} \mathrm{C}$ inactivates mesocercariae [70]. The survival of the larvae of $A$. alat $a$ at the temperatures in refrigerators $\left(4\right.$ to $8{ }^{\circ} \mathrm{C}$ ) is very high, even during long-term storage; therefore, the potential risk for consumers remains high [58]. To date, there is no precise information about the doses required for infections. However, after analyzing confirmed alariosis cases, it can be assumed that the severity of the symptoms is correlated with the number of larvae 
taken in $[62,64,65,71]$. According to current knowledge, heat treatment is the most effective method for the inactivation of $A$. alata mesocercariae in wild boar meat. Heating at $72{ }^{\circ} \mathrm{C}$ for 2 min kills mesocercariae; therefore, the meat becomes fit for consumption [72]. In the work of Portier et al. (2011), it was shown that A. alata larvae could survive for at least five days when frozen $\left(-18^{\circ} \mathrm{C}\right)$ [3]. The most effective method for killing these flukes-as in the case of Trichinella spp.-is cooking at $71^{\circ} \mathrm{C}$ [38]. In addition, hygienic production is very important for minimizing the risks to consumers, as smear infections can occur during meat processing $[62,64,66,71]$. It is difficult to estimate the risk linked with the consumption of raw or undercooked meat products made from organic or free-range pigs. Studies conducted in Serbia on diaphragm samples collected from 72 free-range pigs showed that the percentage of samples infected with A. alata mesocercariae was $2.77 \%$. The researchers then underlined that the risk of human alariosis increases in regions where there is a tradition of making homemade pork products [73]. In addition, in other countries, delicacies made from raw ground pork are very popular dishes. Among them, there are types of fresh sausages, such as Italian sausage, bratwurst, Polish steak tartare, and German mett. These products are made from chopped, ground, or even pureed uncooked pork meat. In some territories, such as France and some Nordic countries, the consumption of game meat is related to the historical culture, in which this type of meat is shared among hunters and their families. Therefore, this group of consumers is especially exposed to the consumption of meat infected by A. alata [36,58]. In 2014, in Germany, studies were performed to determine the survival rate of $A$. alata larvae during the production of raw cured meat products, such as raw ham, salami, and raw sausage. These studies intended to clarify whether mesocercariae are eliminated during the production of these products and if traditional meat products play a role as sources of $A$. alata infections in humans. In the experiment, the meats of wild boars and raccoons that were positive for the presence of A. alata were used. A comparison of the three different technological processes showed that no live larvae were found in any of the ready-made hams, which proved that $100 \%$ of $A$. alata mesocercariae were inactivated during production. However, $11.9 \%$ of salami sausages and $18.2 \%$ of the second type of raw sausage contained mesocercariae $24 \mathrm{~h}$ after preparation in the initial fermentation stage. Therefore, even tasting the meat during production may lead to an intake of $A$. alata mesocercariae. These results indicate that the consumption of raw sausages in particular may be risky for consumers, especially if these products are consumed immediately after production [74]. The German Federal Institute for Risk Assessment (BfR) conducted an evaluation to determine the risk of infection with parasites after consumption of game meat. This type of product is generally consumed in low amounts in Germany (200 to $400 \mathrm{~g}$ per person each year). However, the consumption of game meat in Germany has increased in recent years, and a certain group of people, including hunters, their relatives, and their friends, can consume 50-90 times more meals containing game each year [75-77]. There is also an increasing interest in medium or rare game meat, which is pink at the core. The document mentioned above includes a recommendation to thoroughly cook game meat, raw game sausages, and raw meat products before consumption [72].

\section{Conclusions}

In 2003, the Swiss Federal Office for the Environment classified A. alata as a parasite in Risk Group 2 with zoonotic potential. It is now considered a potential foodborne parasite [72]. Despite the usually mild symptoms of A. alata infections, these parasites may be dangerous to both animals and humans. People who consume raw or semi-raw products made from wild boars and free-range pigs should be aware of the potential risks caused by $A$. alata [10]. In order to fully estimate the risks associated with the consumption of homemade meat products, further research considering different types of meat processing methods is needed [78]. However, A. alata, as well as other food-borne parasites, can be inactivated in food products by using proper heat treatment and production hygiene. This review on Alaria and alariosis contributes to the concept of One Health, harmonizing 
various compounds and practices that act together to facilitate human health, animal health, and the environment. The article aimed to raise awareness of health management for the disease. To achieve the goal of One Health, we have to bring together the human and animal health sectors and identify the complex epidemiology of the disease. This review provides support to develop effective policies to prevent and manage public health, animal health, and agricultural sectors. The same approaches were indicated by other authors, such as Shamsi (2019), who underline food safety as a global concern that cannot be viewed in isolation and as a matter of importance for all countries [79].

Supplementary Materials: The following is available online at https:/ /www.mdpi.com/article/10 .3390/foods10071614/s1, Video S1: The movements of $A$. alata larvae present in a muscular cyst.

Author Contributions: Conceptualization, M.R. and W.K.-D.; writing—original draft preparation, W.K.-D. and M.R.; writing—review and editing, M.R., E.B.-Z., J.K., J.S. and A.B.; visualization, M.R., J.K. and M.W.; supervision, T.C. All authors have read and agreed to the published version of the manuscript.

Funding: This research was funded by the National Veterinary Research Institute, Pulawy, Poland, Statutory Research project no. S/444, "Assessment of the occurrence of Alaria alata flukes in the wild boar population in Poland".

Conflicts of Interest: The authors declare no conflict of interest.

\section{References}

1. Tack, J. Wild boar (Sus scrofa) populations in Europe: A scientific review of population trends and implications for management. Eur. Landowners' Organ. 2018, 56. Available online: https://www.europeanlandowners.org/images/Wild_Boar_Report_2018/1 22193_WILD_BOAR_GB.pdf (accessed on 12 July 2021).

2. Strazdina, V.J.A.; Sterna, V.; Ikauniece, D. Nutritional characteristics of wild boar meat hunted in Latvia. Proc. Foodbalt 2014, 1, 32-36.

3. Portier, J.; Jouet, D.; Ferte, H.; Gibout, O.; Boireau, P.; Vallee, I. New Data in France on the Trematode Alaria alata (Goeze, 1792) Obtained during Trichinella Inspections. Parasite 2011, 18, 271-275. [CrossRef]

4. Bilska-Zajac, E.; Marucci, G.; Piróg-Komorowska, A.; Cichocka, M.; Różycki, M.; Karamon, J.; Sroka, J.; Bełcik, A.; Mizak, I.; Cencek, T. Occurrence of Alaria alata in wild boars (Sus scrofa) in Poland and detection of genetic variability between isolates. Parasitol. Res. 2021, 120, 83-91. [CrossRef] [PubMed]

5. Berger, E.M.; Paulsen, P. Findings of Alaria alata mesocercariae in wild boars (Sus scrofa, Linnaeus, 1758) in west Hungary (Transdanubia regions). Wien. Tierärztliche Mon. 2014, 101, 120-123.

6. Duscher, G. "Duncker's muscle fluke"-Alaria alata in red foxes from Austria in relation to the occurrence of wild boars. Wien. Tierärztliche Mon. 2011, 98, 251-254.

7. Shoop, W.L.; Corkum, K.C. Transmammary infection of paratenic and definitive hosts with Alaria marcianae (trematoda) mesocercariae. J. Parasitol. 1983, 69, 731-735. [CrossRef] [PubMed]

8. Shoop, W.L.; Corkum, K.C. Epidemiology of Alaria marcinae mesocercariae in Louisiana. J. Parasitol. 1981, 67, 928-931. [CrossRef]

9. Shimalov, V.; Shimalov, V. Helminth fauna of the American mink (Mustela vison Schreber, 1777) in Belorussian Polesie. Parasitol. Res. 2001, 87, 886-887.

10. Riehn, K.; Hamedy, A.; Grosse, K.; Wüste, T.; Lücker, E. Alaria alata in wild boars (Sus scrofa, Linnaeus, 1758) in the eastern parts of Germany. Parasitol. Res. 2012, 111, 1857-1861. [CrossRef]

11. Takeuchi-Storm, N.; Al-Sabi, M.N.S.; Thomsborg, S.M.; Enemark, H.L. Alaria alata Mesocercariae among Feral Cats and Badgers, Denmark. Emerg. Infect. Dis. 2015, 21, 1872-1874. [CrossRef] [PubMed]

12. Wasiluk, A. Alaria alata infection-Threating yet rarely detected trematodiasis. J. Lab. Diag. 2013, 49, 33-37.

13. Strokowska, N.; Klich, D.; Bełkot, Z.; Wiśniewski, J.; Didkowska, A.; Chyla, P.; Anusz, K. The occurrence of Alaria alata mesocercariae in wild boars (Sus scrofa) in north-eastern Poland. Int. J. Parasitol. Parasites Wildl. 2020, 12, 25-28. [CrossRef]

14. Renteria-Solis, Z.; Kolodziej-Sobocinska, M.; Riehn, K. Alaria spp. mesocercariae in Eurasian badger (Meles meles) and wild boar (Sus scrofa) from the Bialowieza Forest, north-eastern Poland. Parasitol. Res. 2018, 117, 1297-1299. [CrossRef]

15. Edwards, S.; Prunier, A.; Bonde, M.; Stockdale, E.A. Special issue-Organic pig production in Europe-Animal health, welfare and production challenges. Org. Agric. 2014, 4, 79-81. [CrossRef]

16. Commission Implementing Regulation. EC No 2015/1375, COMMISSION IMPLEMENTING REGULATION (EU) 2015/1375 of 10 August 2015 Laying Down Specific Rules on Official Controls for Trichinella in Meat. 2015. Available online: https: / / eur-lex.europa.eu/legal-content/EN/TXT/HTML/?uri=CELEX:32015R1375\&from=EN (accessed on 12 July 2021).

17. Rossi, P.; de Smet, K.; Pozio, E. Detection of Trichinella Larvae in Meat: Comparison of ISO 18743:2015 with Regulation (EU) 2015/1375. Food Anal. Methods 2017, 10, 634-639. [CrossRef]

18. Duncker, H.C.J. Distomeen in Schweinefleisz. Zschr mikr. Fleischschau 1881, 2, 22-24. 
19. Duncker, H.C.J. Muskel-Distomeen. Zschr mikr. Fleischschau 1881, 2, 141.

20. Duncker, H.C.J. Distomeen im Schweinefleisch. Zschr mikr. Fleischschau 1884, 3, 39-42.

21. Duncker, H.C.J. Die Muskel-Distomeen. Berl. Münchener Tierärztliche Wochenschr. 1896, 24, $279-282$.

22. Duncker, H.C.J. Die Muskel-Distomeen. Zschr Fleisch. Milchhyg. 1897, 7, 197-198.

23. Bugge, G. Der muskelegel Dunckers beim frosch. Zschr Fleisch. Milchhyg. 1942, 54, 73-76.

24. Stefański, W.; Tarczyński, S. Sur le developpement de l'Agamodistomum suis Duncker, 1881. Acta Parasitol. Pol. 1953, 1, 149-154.

25. Bosma, N.J. Alaria mustelae sp. nov., a trematode requiring four hosts. Science 1931, 74, 521-522. [CrossRef]

26. Olivier, L.; Odolaug, T.O. A new mesocercaria (Trematoda: Strigeata) with a note on its further developement. J. Parasitol. 1938, 24, 369-374. [CrossRef]

27. Johnson, A.D. Life history of Alaria marcianae (La Rue, 1917) Walton, 1949 (Trematoda: Diplostomatidae). J. Parasitol. 1968, 54, 324-332. [CrossRef]

28. Compton, T.L. Alaria arisaemoides Augustine and Uribe, 1927 (Strigeidae) from interior Alaska. Can. J. Zool. 1969, $47,1420-1421$. [CrossRef]

29. Pearson, J.C. Studies on the life cycles and morphology of the larval stages of Alaria arisaemoides Augustine and Uribe, 1927 and Alaria canis La Rue and Fallis, 1936 (trematode: Diplostomidae). Can. J. Zool. 1956, 34, 295-387. [CrossRef]

30. Sekerak, A.D. Alaria taxideae Swanson and Erickson, 1946 in pine marten from central Alaska (Trematode: Diplostomatidae). Can. J. Zool. 1969, 47, 266. [CrossRef] [PubMed]

31. Nacheva, L.V.; Manikovskaya, N.S. Structure of some strigeatas' organ of Brandes. In Proceedings of the Sbornik Nauchnykh Statei po Materialam Mezhdunarodnol̆ Nauchnor̆ Konferentsii, Teoriya i Praktika Bor'by s Parazitarnymi Boleznyami, Posvyashaetsya 90-Letiyu so Dnya Rozhdeniya Andreya Stefanovicha Bessonova, Vypusk 20, Moscow, Russia, 15-17 May 2019 ; pp. $399-403$.

32. Möhl, K.; Grosse, K.; Hamedy, A.; Wüste, T.; Kabelitz, P.; Lücker, E. Biology of Alaria spp. and human exposition risk to Alaria mesocercariae-A review. Parasitol. Res. 2009, 105, 1-15. [CrossRef] [PubMed]

33. Wójcik, A.R.; Grygon-Franckiewicz, B.; Żbikowska, B. Current data of Alaria alata (Goeze, 1782) according to own studies. Vet. Med. 2002, 58, 517-519.

34. Chmurzyńska, E.; Różycki, M.; Bilska-Zając, E.; Karamon, J.; Cencek, T. Alaria alata-Potential threat for humans, prevalence and diagnostic measures. Vet. Life 2013, 88, 780-784.

35. Karamon, J.; Sroka, J.; Dąbrowska, J.; Bilska-ając, E.; Skrzypek, K.; Różycki, M.; Zdybel, J.; Cencek, T. Distribution of parasitic helminths in the small intestine of the red fox (Vulpes vulpes). Pathogens 2020, 9, 477. [CrossRef] [PubMed]

36. Anonymous. Wid Boar Meat Can Contain Duncker's Muscle Fluke, 2017 (Updated BfR Opinion No. 011/2017). BfR. Available online: https://mobil.bfr.bund.de/cm/349/wild-boar-meat-can-contain-Dunckers-muscle-fluke.pdf (accessed on 12 July 2021).

37. Ozolina, Z.; Deksne, G. Effectiveness of two methods for mesocercariae of Alaria alata detection in wild boars (Sus scrofa). EEB 2017, 15, 25-28.

38. Gamble, H.R.; Bessonov, A.S.; Cuperlovic, K.; Gajdhar, A.A.; van Knapen, F.; Noeckler, K.; Schenone, H.; Zhu, X. International Commission on Trichinellosis: Recommendations on methods for the control of Trichinella in domestic and wild animals intended for human consumption. Vet. Parasitol. 2000, 93, 393-408. [CrossRef]

39. Paulsen, P.; Forejtek, P.; Hutarova, Z.; Vodnansky, M. Alaria alata mesocercariae in wild boar (Sus scrofa, Linnaeus, 1758) in south regions of the Czech Republic. Vet. Parasitol. 2013, 197, 384-387. [CrossRef]

40. Di Cerbo, A.R.; Manfredi, M.T.; Bergoli, M.; Ferro Milone, N.; Cova, M. Wild carnivores as source of zoonotic helminths in north-eastern Italy. Helminthologia 2008, 45, 13-19. [CrossRef]

41. Gawor, J.; Malczewski, A.; Rocki, B.; Malczewska, M.; Borecka, A. Prevalence of the dangerous for humans tapeworm Echinococcus multilocularis in red foxes in Poland. Vet. Med. 2004, 60, 489-491.

42. Miterpáková, M.; Hurniková, Z.; Antolová, D.; Dubinský, P. Endoparasites of red fox (Vulpes vulpes) in the Slovak Republic with the emphasis on zoonotic species Echinococcus multilocularis and Trichinella spp. Helminthologia 2009, 46, 73-79. [CrossRef]

43. Reperant, L.A.; Hegglin, D.; Fischer, C.; Kohler, L.; Weber, J.-M.; Deplazes, P. Influence of urbanization on the epidemiology of intestinal helminths of the red fox (Vulpes vulpes) in Geneva, Switzerland. Parasitol. Res. 2007, 101, 605-611. [CrossRef]

44. Saeed, I.; Maddox-Hyttel, C.; Monrad, J.; Kapel, C.M.O. Helminths of red foxes (Vulpes vulpes) in Denmark. Vet. Parasitol. 2006, 139, 168-179. [CrossRef] [PubMed]

45. Tylkowska, A.; Pilarczyk, B.; Pilarczyk, R.; Zyśko, M.; Tomza-Marciniak, A. The presence of Alaria alata fluke in the red fox (Vulpes vulpes) in the north-western Poland. Jpn. J. Vet. Res. 2018, 66, 203-208.

46. Murphy, T.M.; O'Connell, J.; Berzano, M.; Dold, C.; Keegan, J.D.; McCann, A.; Murphy, D.; Holden, N.M. The prevalence and distribution of Alaria alata, a potential zoonotic parasite, in foxes in Ireland. Parasitol. Res. 2012, 111, 283-290. [CrossRef] [PubMed]

47. Karamon, J.; Dąbrowska, J.; Kochanowski, J.; Samorek-Pieróg, M.; Sroka, J.; Różycki, M.; Bilska-Zając, E.; Zdybel, J.; Cencek, T. Prevalence of intestinal helminths of red foxes (Vulpes vulpes) in central Europe (Poland): A significant zoonotic threat. Parasites Vectors 2018, 11, 436. [CrossRef] [PubMed]

48. Bružinskaitè-Schmidhalter, R.; Šarkiūnas, M.; Malakauskas, A.; Mathis, A.; Torgerson, P.R.; Deplazes, P. Helminths of red foxes (Vulpes vulpes) and raccoon dogs (Nyctereutes procyonoides) in Lithuania. Parasitology 2012, 139, 120-127. [CrossRef]

49. Ramisz, A.; Nicpoń, J.; Balicka-Ramisz, A.; Pilarczyk, B.; Pacoń, J.; Piekarska, J. The prevalence of gastro-intestinal helminths in red foxes (Vulpes vulpes) in the south-west part of Poland. Tierärztliche Umsch. 2004, 59, 601-604. 
50. Borgsteede, F.H. Helminth parasites of wild foxes (Vulpes vulpes L.) in The Netherlands. Z. Parasitenkd. 1984, 70, $281-285$. [CrossRef]

51. Franssen, F.; Nijsse, R.; Mulder, J.; Cremers, H.; Dam, C.; Takumi, K.; van der Giessen, J. Increase in number of helminth species from Dutch red foxes over a 35-year period. Parasites Vectors 2014, 7, 166. [CrossRef]

52. Fiocchi, A.; Gustinelli, A.; Gelmini, L.; Rugna, G.; Renzi, M.; Fontana, M.C.; Poglayen, G. Helminth parasites of the red fox Vulpes vulpes (L., 1758) and the wolf Canis lupus italicus Altobello, 1921 in Emilia-Romagna, Italy. Ital. J. Zool. 2016, 83, 503-513. [CrossRef]

53. Rajković-Janje, R.; Marinculić, A.; Bosnić, S.; Benić, M.; Vinković, B.; Mihaljević, Ž. Prevalence and seasonal distribution of helminth parasites in red foxes (Vulpes vulpes) from the Zagreb County (Croatia). Z. Jagdwiss 2002, 48, 151-160. [CrossRef]

54. Papadopoulos, H.; Himonas, C.; Papazahariadou, M.; Antoniadou-Sotiriadou, K. Helminths of foxes and other wild carnivores from rural areas in Greece. J. Helminthol. 2009, 71, 227-232. [CrossRef] [PubMed]

55. Smith, G.C.; Gangadharan, B.; Taylor, Z.; Laurensol, M.K.; Bradshaw, H.; Hide, G.; Hughes, J.M.; Dinkel, A.; Romig, T.; Craig, P.S. Prevalence of zoonotic important parasites in the red fox (Vulpes vulpes) in Great Britain. Vet. Parasitol. 2003, 118, 133-142. [CrossRef]

56. Riehn, K.; Lalkovski, N.; Hamedy, A.; Lücker, E. First detection of Alaria alata mesocercariae in wild boars (Sus scrofa Linnaeus, 1758) from Bulgaria. J. Helminthol. 2014, 88, 247-249. [CrossRef] [PubMed]

57. Sailer, A.; Glawisching, W.; Irschik, I.; Lücker, E.; Riehn, K.; Paulsen, P. Findings of Alaria alata mesocercariae in wild boar in Austria: Current knowledge, identification of risk factors and discussion of risk management options. Wien. Tierärztliche Mon. 2012, 99, 346-352.

58. French Agency for Food, Environmental and Occupational Health and Safety. Opinion on the Presence of Mesocercarial Parasites of the Trematode Alaria alata in Wild Boar Meat. 2015. Available online: https:/ / www.anses.fr/en/system/files/BIORISK201 5SA0052EN.pdf (accessed on 12 July 2021).

59. Paulsen, P.; Kukla, P.; Bachkönig, N. An update on findings of Alaria alata mesocercariae in wild boar from Austria. In Trends in Game Meat Hygiene: From Forest to Fork; Paulsen, P., Bauer, A., Smulders, F.J.M., Eds.; Wageningen Academic Publishers: Wageningen, The Netherlands, 2014; pp. 203-210.

60. Tăbăran, F.; Sándor, A.D.; Marinov, M.; Cătoi, C.; Mihalca, A.D. Alaria alata infection in european mink. Emerg. Infect. Dis. 2013, 19, 1547-1549. [CrossRef]

61. Erlich, I. Paraziticka fauna pasa s podrucja grada Zagreba. Vet. Arh. 1938, 8, 531-587.

62. Fernandes, B.J.; Cooper, J.D.; Cullen, J.B.; Freeman, R.S.; Ritchie, A.C.; Scott, A.A.; Stuart, P.F. Systemic infection with Alaria americana (Trematoda). Can. Med Assoc. J. 1976, 115, 1111-1114. [PubMed]

63. Freeman, R.S. Helminth parasites of the red fox in Finland 1963-1964. In Proceedings of the First International Congress of Parasitology, Roma, Italy, 21-26 September 1964; p. 482.

64. Kramer, M.H.; Eberhard, M.L.; Blankenberg, T.A. Respiratory symptoms and subcutaneous granuloma caused by mesocercariae: A case report. Am. J. Trop Med. Hyg. 1996, 55, 447-448. [CrossRef]

65. Beaver, P.C.; Little, M.D.; Tucker, C.F.; Reed, R.J. Mesocercaria in the Skin of Man in Louisiana. Am. J. Trop Med. Hyg. 1977, 26, 422-426. [CrossRef]

66. McDonald, H.R.; Kazacos, K.R.; Schatz, H.; Johnson, R.N. Two cases of intraocular infection with Alaria mesocercaria (Trematoda). Am. J. Ophthalmol. 1994, 117, 447-455. [CrossRef]

67. Dollfus, R.P.; Chabaud, A.G. Distomum musculorum suis, mesocercairia of Alaria alata in the wild boar Sus scrofa L. Ann. Parasitol. Hum. Comp. 1953, 28, 354-364.

68. Shimalov, V.V.; Shimalov, V.T. Helminth fauna of the wolf (Canis lupus Linnaeus, 1758) in Belorussian Polesie. Parasitol. Res. 2000, 86, 163-164. [CrossRef] [PubMed]

69. Gérard, C.; Franssen, F.; La Carbona, S.; Monteiro, S.; Cozma-Petrut, A.; Utaaker, K.S.; Jambrak, R.A.; Rowan, N.; RodriguezLazaro, D.; Nasser, A.; et al. Inactivation of parasite transmission stages: Efficacy of treatments on foods of non-animal origin. Food Sci. Technol. 2019, 91, 12-23. [CrossRef]

70. González-Fuentes, H.; Hamedy, A.; Koethe, M.; von Borell, E.; Luecker, E.; Riehn, K. Effect of temperature on the survival of Alaria alata mesocercariae. Parasitol. Res. 2015, 114, 1179-1187. [CrossRef] [PubMed]

71. Shea, M.; Maberley, A.L.; Walters, J.; Freeman, R.S.; Fallis, A.M. Intraretinal larval trematode. Am. J. Ophthalmol. 1973, 77, 784-791.

72. German Federal Institute for Risk Assessment (BfR). Game Meat: Health Assessment of Human-Pathogenic Parasites. Opinion No.045/2018, 1st ed.; German Federal Institute for Risk Assessment: Berlin, Germany, 2018.

73. Gavrilovic, P.; Pavlovic, I.; Todorovic, I. Alaria alata mesocercariae in domestic pigs and wild boars in South Banat, northern Serbia. Comp. Immunol. Microbiol. Infect. Dis. 2019, 63, 142-144. [CrossRef] [PubMed]

74. González-Fuentes, H.; Hamedy, A.; von Borell, E.; Luecker, E.; Riehn, K. Tenacity of Alaria alata mesocercariae in home-made German meat products. Int. J. Food Microbiol. 2014, 176, 9-14. [CrossRef]

75. Krostitz, W. Der Wildfleischmarkt. Fleischwirtschaft 1996, 76, 7.

76. Haldimann, M.; Baumgartner, A.; Zimmerli, B. Intake of lead from game meat-Arisk to consumers' health? Eur. Food Res. Technol. 2002, 215, 375-379. [CrossRef]

77. Hoffman, L.C.; Wiklund, E. Game and venison-Meat for the modern consumer. Meat Sci. 2006, 74, 197-208. [CrossRef] [PubMed] 
78. González-Fuentes, H.; Riehn, K.; Koethe, M.; von Borell, E.; Luecker, E.; Hamedy, A. Effects of in vitro conditions on the survival of Alaria alata mesocercariae. Parasitol. Res. 2014, 113, 2983-2989. [CrossRef] [PubMed]

79. Shamsi, S. Seafood-borne parasitic diseases: A “One Health" approach is needed. Fishes 2019, 4, 9. [CrossRef] 